\title{
A General Strategy to Fabricate Metal-Incorporated Pyrolysis-Free Covalent Organic Framework for Efficient Oxygen Evolution Reaction
}

Zhi Gao, Le Le Gong, Xiang Qing He, Xue Min Su, Long Hui Xiao, Feng Luo*

State Key Laboratory of Nuclear Resources and Environment, School of Chemistry,

Biology and Materials Science, East China University of Technology, Nanchang 330013, P. R. China

E-mail: ecitluofeng@163.com

Corresponding author: F. Luo, ecitluofeng@163.com 


\section{Experimental}

Characterizations. Powder X-ray diffraction (PXRD) data of samples were recorded at room temperature on a Bruker AXSD8 Discover powder diffractometer. $\mathrm{Cu}$ Karadiation $(\lambda=0.15418 \mathrm{~nm}, 40 \mathrm{kV}, 30 \mathrm{Ma})$ was used as an X-ray source. The simulated powder patterns of COF-SO $\mathrm{SO}_{3} \mathrm{H}$ and $\mathrm{NH}_{4} @ \mathrm{COF}-\mathrm{SO}_{3} \mathrm{H}$ were determined by Mercury 1.4. SEM measurement was carried out using a Hitachi S-4800 microscope which was combined with energy-dispersive X-ray spectroscopy (EDX) to determine the metal composition and distribution. Transmission electron microscopy (TEM) and high-resolution TEM (HRTEM) images were collected on a JEOL 2100 microscope operated at an accelerating voltage of $200 \mathrm{kV}$. Bruker VERTEX70 spectrometer was used to obtain infrared (IR) spectra within the region of $500-4000 \mathrm{~cm}^{-1}$. Low temperature $\mathrm{N}_{2}$ adsorption-desorption isotherms were recorded on a Belsorp-max at $77 \mathrm{~K}$. The total specific surface areas were evaluated with the multipoint Brunauer-Emmett-Teller (BET) method. Elemental analysis of metal in $\mathrm{Ni}_{\mathrm{x}} \mathrm{Fe}_{1-\mathrm{x}} @ \mathrm{COF}-\mathrm{SO}_{3}(\mathrm{x}=0,0.2,0.5,0.8,1.0)$ was performed using a Shimadzu ICPS-7500 inductively coupled plasma emission spectrometer (ICP-AES). X-ray photoelectron spectra (XPS) measurements were carried out on Thermo Scientific ESCALAB $250 \mathrm{Xi}$ spectrometer at a base pressure of $2 \times 10^{-9} \mathrm{~Pa}$ with $\mathrm{Al} \mathrm{Ka}$ radiation. The binding energy calibration of all spectra was referenced to the $\mathrm{C} 1 \mathrm{~s}$ signal at $284.6 \mathrm{eV}$.

Density functional theory calculations. The periodic density functional theory 
calculations were performed using the Vienna Ab initio Simulation Package (VASP) code to optimize the structures in this work. The Perdew-Burke-Ernzerhof (GGA-PBE) functional was utilized to calculate the exchange-correlation energy, and the project-augmented wave generalized gradient approximation (PAW-GGA) pseudopotentials were adopted to describe the electron-ion interaction. All the structures were optimized aiming to the global energy minimum, fully relaxed until the residual force convergence value on each tom being less $0.05 \mathrm{eV} / \AA$. The Brillouin zone was sampled by $3 \times 3 \times 1$ Gamma k-point mesh and the wave functions were expanded using a plane-wave basis set with kinetic energy cutoff of $500 \mathrm{eV}$. Spin-polarization was calculated and the lowest energy magnetic configurations were identified. All of the above structures were established by Materials Studio.

Synthesis of 2,4,6-triformylphloroglucinol, 2,5-diaminobenzenesulfonic acid, $\mathrm{COF}_{-} \mathrm{SO}_{3} \mathrm{H} \quad$ and $\quad \mathrm{NH}_{4} @ \mathbf{C O F}-\mathrm{SO}_{3} . \quad 2,4,6$-triformylphloroglucinol, 2,5-diaminobenzenesulfonic acid, COF-SO $\mathrm{SH}_{3} \mathrm{H}$ and $\mathrm{NH}_{4} @ \mathrm{COF}-\mathrm{SO}_{3}$ were synthesized by the same procedures reported by our previous work [S1].

Synthesis of $\mathrm{Ni}_{\mathrm{x}} \mathrm{Fe}_{1-\mathrm{x}} @ \mathrm{COF}-\mathrm{SO}_{3}(\mathrm{x}=\mathbf{0}, \mathbf{0 . 2}, \mathbf{0 . 5}, \mathbf{0 . 8}, 1.0) .20 \mathrm{mg}$ of $\mathrm{NH}_{4} @$ COF-SO $3, x \mathrm{~mL} \mathrm{NiCl}{ }_{2} \cdot 6 \mathrm{H}_{2} \mathrm{O}\left(\mathrm{Ni}^{2+}, 1000 \mathrm{ppm}\right)$ and $(1-\mathrm{x}) \mathrm{mL} \mathrm{FeSO}_{4} \cdot 7 \mathrm{H}_{2} \mathrm{O}$ $\left(\mathrm{Fe}^{2+}, 1000 \mathrm{ppm}\right)$ were added to $5 \mathrm{~mL}$ glass bottle and then stirred under room temperature for $1 \mathrm{~h}$. After that, the sample was collected by filtration, washed with deionized water for several times and dried in a vacuum oven at $60{ }^{\circ} \mathrm{C}$ overnight.

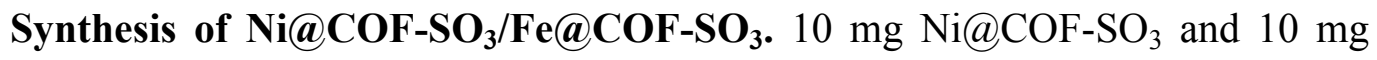
$\mathrm{Fe} @ \mathrm{COF}-\mathrm{SO}_{3}$ were mixed uniformly by grinding. The resulting mixture was denoted 
as $\mathrm{Ni} @ \mathrm{COF}-\mathrm{SO}_{3} / \mathrm{Fe} @ \mathrm{COF}-\mathrm{SO}_{3}$.

Electrochemical measurements. The OER electrocatalytic properties were studied on a CHI660E electrochemical workstation (CH Instruments Inc., Shanghai) in a standard three-electrode system using $1 \mathrm{M} \mathrm{KOH}$ aqueous solution as electrolyte, a carbon electrode as counter electrode, a saturated calomel electrode as reference electrode and the as-prepared catalyst as working electrode. To prepare working electrode, a mixture of $3 \mathrm{mg}$ sample and $3 \mathrm{mg}$ carbon powder was added into $1 \mathrm{~mL}$ solution containing $0.95 \mathrm{~mL}$ ethyl alcohol and $50 \mu \mathrm{L}$ Nafion solutions, followed by ultrasonication for $30 \mathrm{~min}$. Finally, $50 \mu \mathrm{L}$ of above ink was dropped on the carbon paper and then dried at room temperature. The polarization data was collected using linear sweep voltammetry (LSV) measurements at a scan rate of $5 \mathrm{mV} \mathrm{s}^{-1}$ in an $\mathrm{O}_{2}$-saturated $1.0 \mathrm{M} \quad \mathrm{KOH}$. Electrochemical impedance spectroscopy (EIS) measurements were performed at the overpotential of $308 \mathrm{mV}$ ranging a frequency from $100 \mathrm{kHz}$ to $0.1 \mathrm{~Hz}$. The electrochemically active surface area (ECSA) was determined by measuring the double-layer capacitance $\left(\mathrm{C}_{\mathrm{dl}}\right)$ with cyclic voltammetry method. A series of scan rates ranging from 10 to $80 \mathrm{mV} / \mathrm{s}$ were applied to plot the capacitive density at $1.28 \mathrm{~V}$ vs RHE against the scan rate. The resulting slope is twice of $\mathrm{C}_{\mathrm{dl}}$, which is used to estimate the ECSA.

Turnover frequency (TOF) values of catalysts were calculated by the standard equation: $\mathrm{TOF}=(J \times A) /(4 \times F \times \mathrm{n})$, where $J\left(\mathrm{~mA} / \mathrm{cm}^{2}\right)$ is the current density at an overpotential of $300 \mathrm{mV} ; A$ is the surface area of electrode $\left(1 \mathrm{~cm}^{2}\right) ; F$ stands for the Faraday constant $(96485 \mathrm{C} / \mathrm{mol})$; $\mathrm{n}$ is molar number of active sites on the electrode. 
The mass activity (MA) is calculated according to the equation: $\mathrm{MA}=J / m$, where $J$ $\left(\mathrm{mA} / \mathrm{cm}^{2}\right)$ is the current density at a given overpotential of $300 \mathrm{mV}$; $\mathrm{m}$ is the mass of active sites deposited onto the electrode. All metals in $\mathrm{Ni}_{\mathrm{x}} \mathrm{Fe}_{1-\mathrm{x}} @ \mathrm{COF}-\mathrm{SO}_{3}(\mathrm{x}=0,0.2$, $0.5,0.8,1)$ samples are assumed to be active sites and the metal content was determined by ICP-AES.

The Faradaic efficiency was determined by comparing the experimentally produced gas volume with the theoretically calculated one by the equation of Faradaic efficiency $=V_{\text {experimental }} / V_{\text {theoretical }}$. The experiment volume of $\mathrm{O}_{2}\left(V_{\text {experimental }}\right)$ was obtained by experimental data and the theoretical volume of $\mathrm{O}_{2}$ of ( $\left.V_{\text {theoretical }}\right)$ can be calculated by the formula of $V_{\text {theoretical }}=J \cdot t \cdot V_{m} / n \cdot F$, where $J$ is the current density; $\mathrm{t}$ is the measured time; $V_{m}$ is the molar volume of $\mathrm{O}_{2}$ in $1 / \mathrm{mol} ; n$ is the number of electrons required for one molecule $\mathrm{O}_{2}$ and $\mathrm{F}$ is the Faraday constant $(96485 \mathrm{C} / \mathrm{mol})$. 


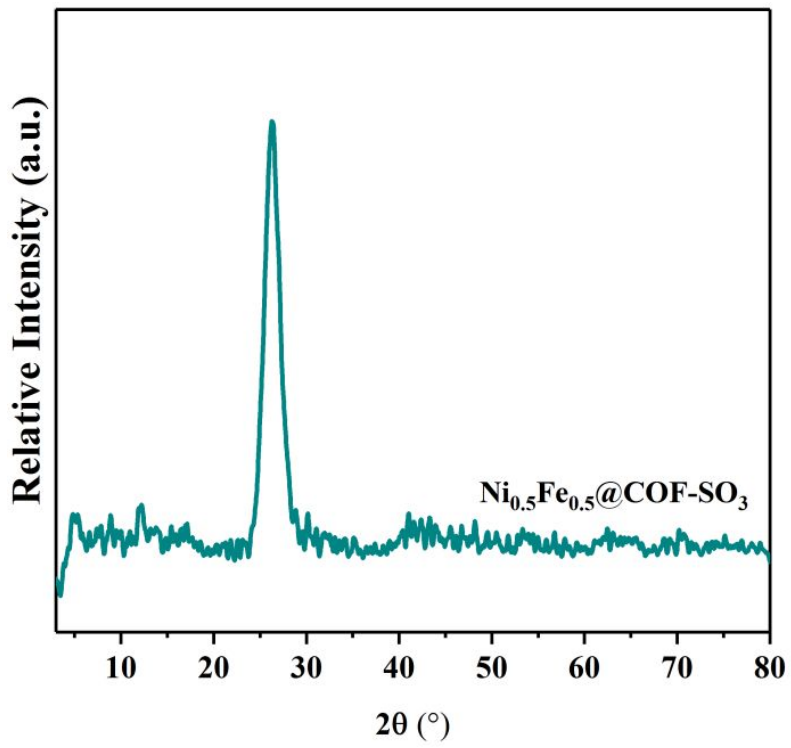

Figure S1. XRD patterns of $\mathrm{Ni}_{0.5} \mathrm{Fe}_{0.5} @ \mathrm{COF}-\mathrm{SO}_{3}$ from $3^{\circ}$ to $80^{\circ}$ (2theta). 


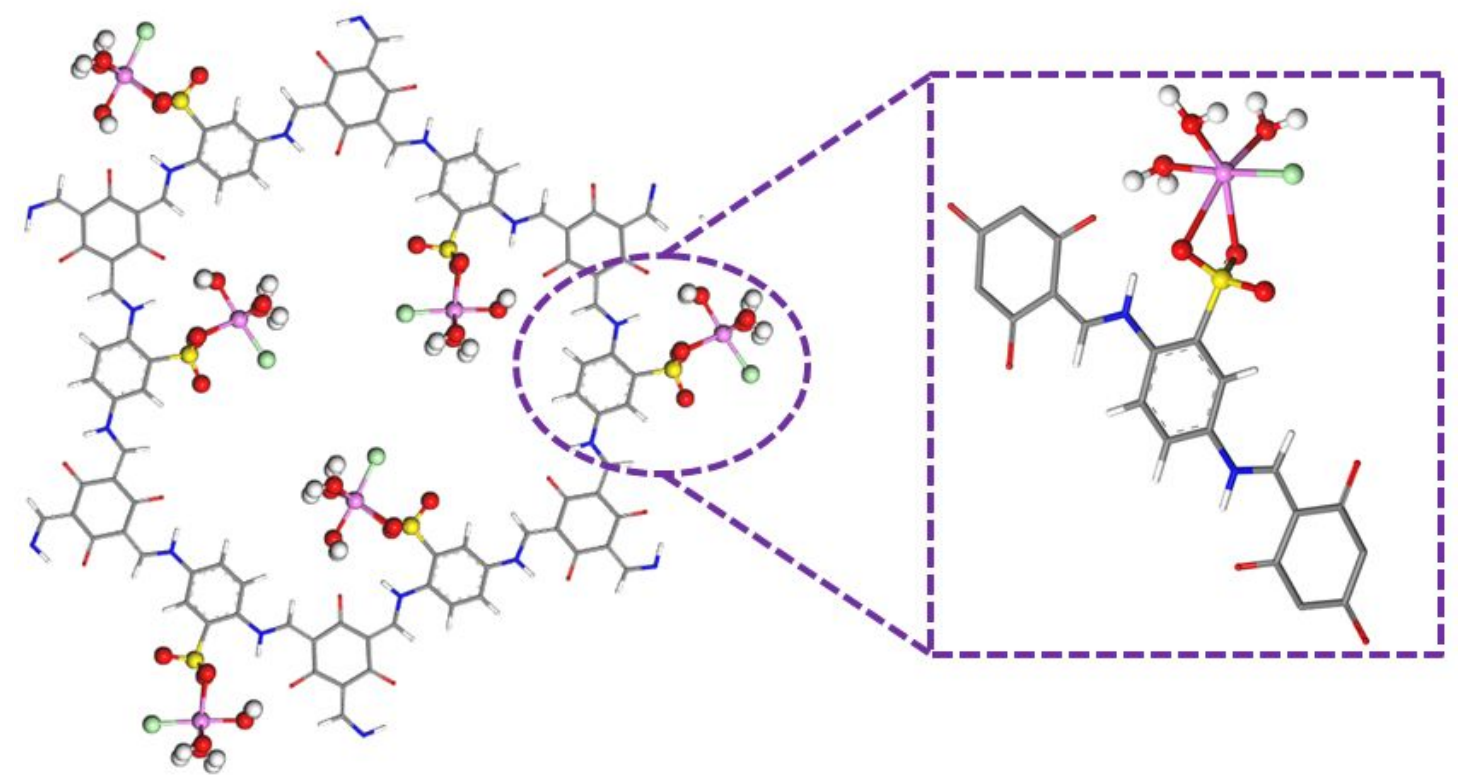

Figure S2. View of the structure of $\mathrm{Ni} @ \mathrm{COF}-\mathrm{SO}_{3}$ 

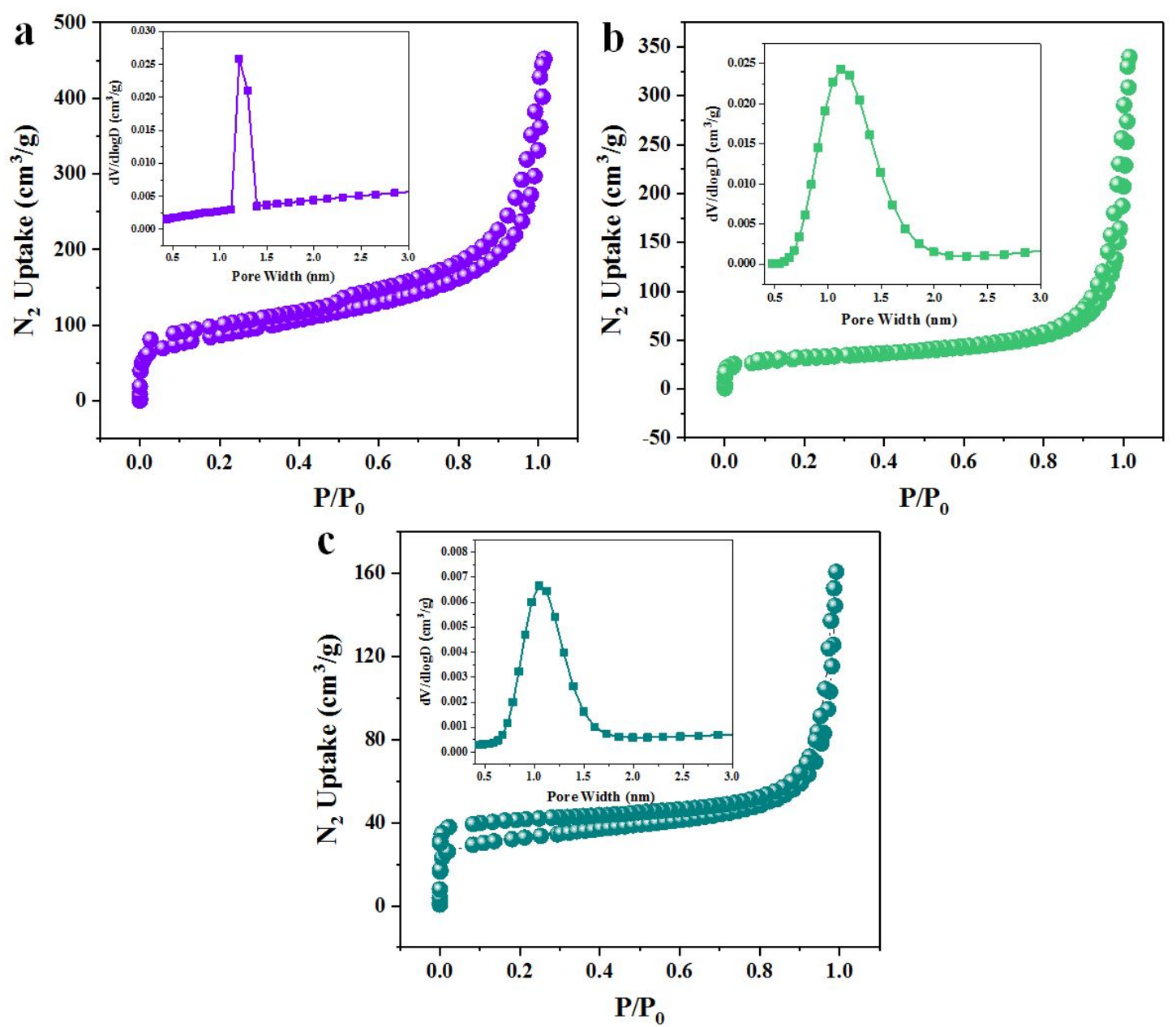

Figure S3. $77 \mathrm{~K}$ nitrogen adsorption isotherm of $\mathrm{COF}-\mathrm{SO}_{3} \mathrm{H}$ (a) [S1], $\mathrm{NH}_{4} @ \mathrm{COF}-\mathrm{SO}_{3}$ (b) [S1] and $\mathrm{Ni}_{0.5} \mathrm{Fe}_{0.5} @ \mathrm{COF}-\mathrm{SO}_{3}$ (c) with the inset for the distribution of pore size. 

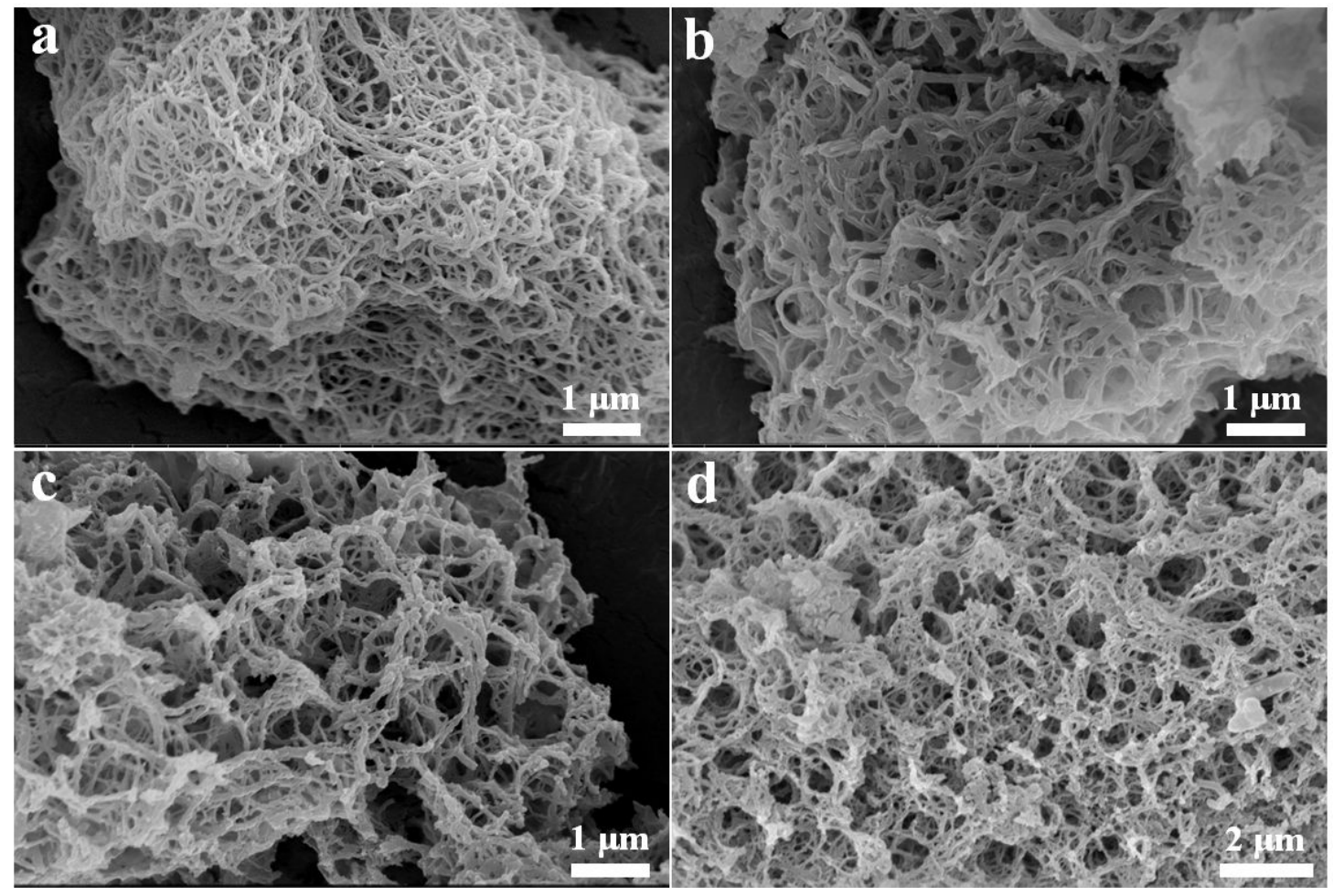

Figure S4. SEM images of $\mathrm{Ni@COF-SO}$

(a), $\mathrm{Fe} @ \mathrm{COF}-\mathrm{SO}_{3}$

(b),

$\mathrm{Ni}_{0.2} \mathrm{Fe}_{0.8} @ \mathrm{COF}-\mathrm{SO}_{3}(\mathrm{c})$ and $\mathrm{Ni}_{0.8} \mathrm{Fe}_{0.2} @ \mathrm{COF}-\mathrm{SO}_{3}(\mathrm{~d})$. 


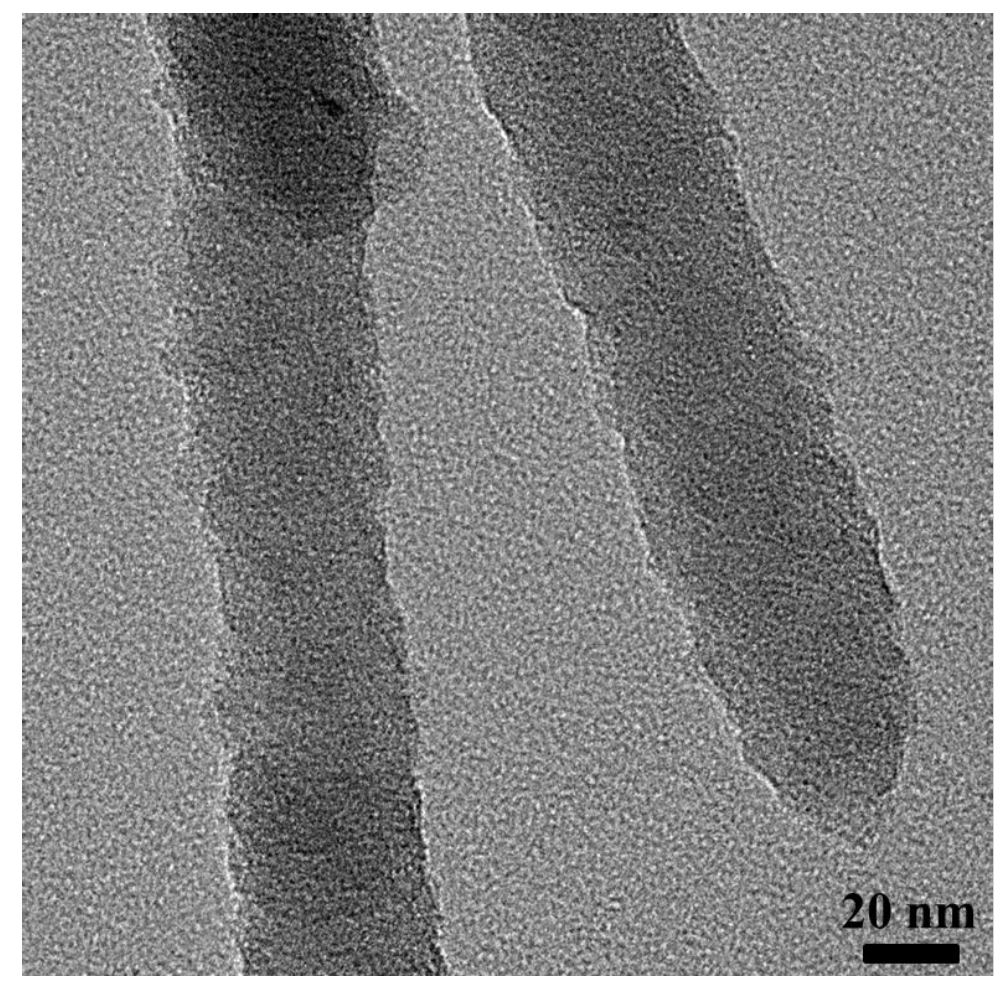

Figure S5. HRTEM image of $\mathrm{Ni}_{0.5} \mathrm{Fe}_{0.5} @ \mathrm{COF}-\mathrm{SO}_{3}$. 


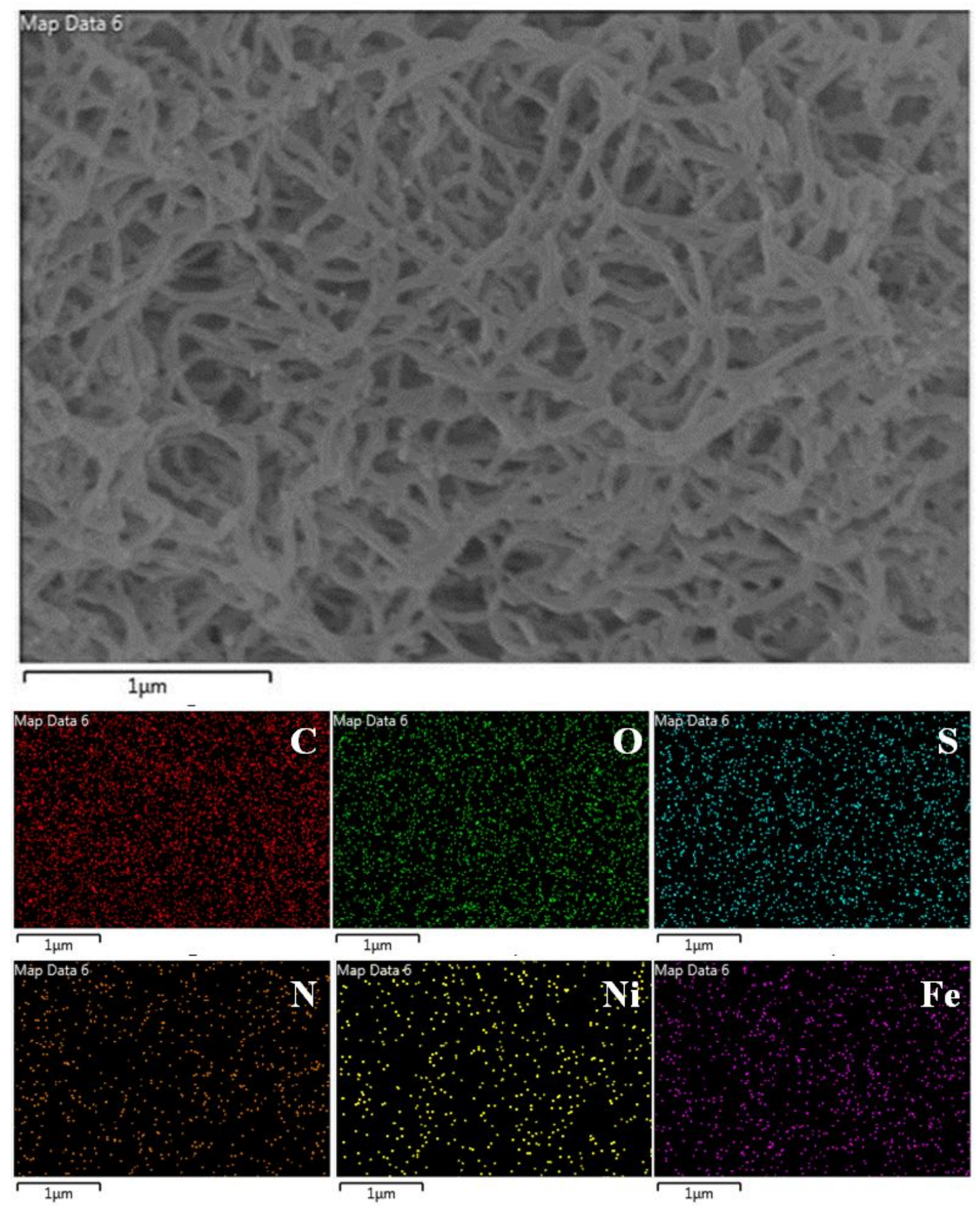

Figure S6. SEM image and SEM-EDS mapping of $\mathrm{Ni}_{0.5} \mathrm{Fe}_{0.5} @ \mathrm{COF}-\mathrm{SO}_{3}$. 


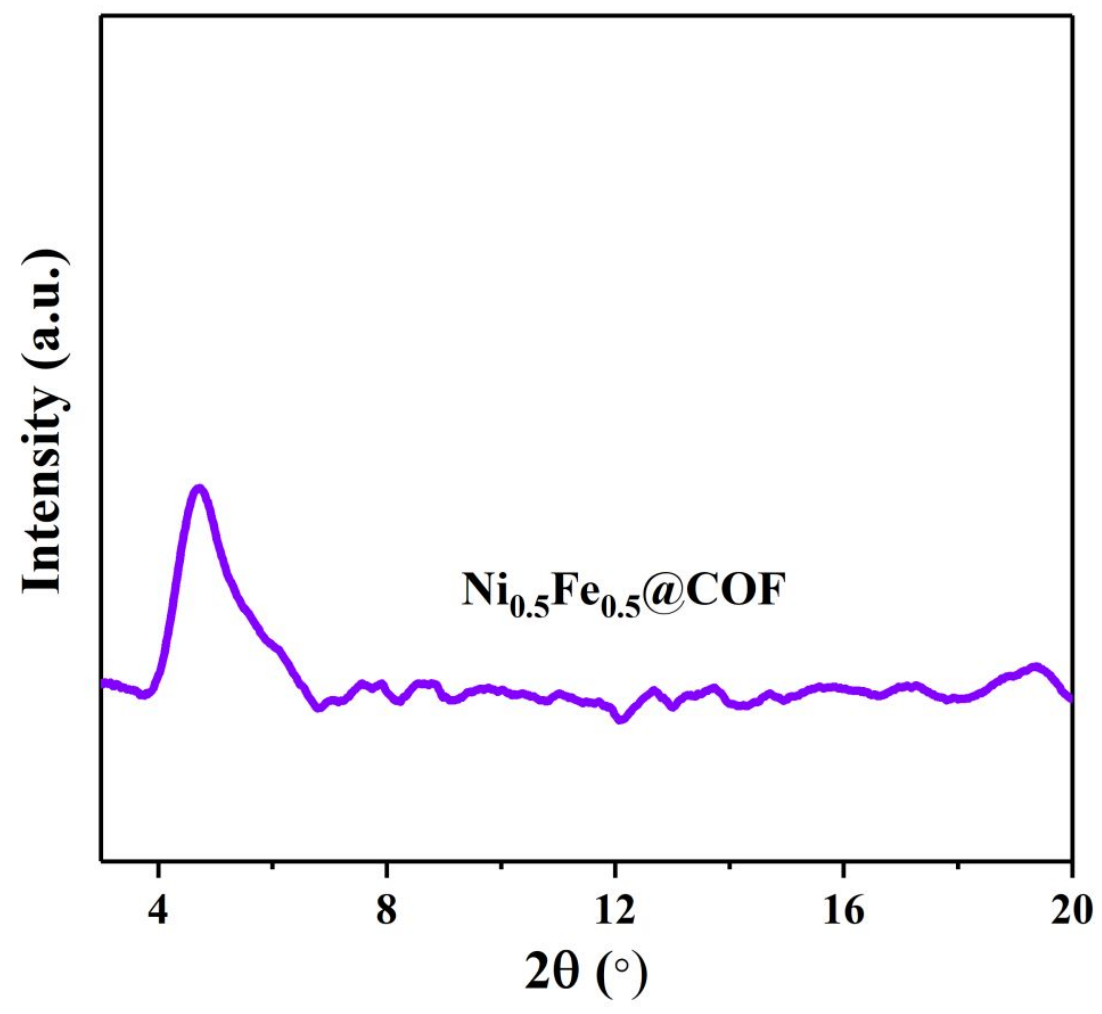

Figure S7. XRD patterns of - $\mathrm{SO}_{3} \mathrm{H}$-free $\mathrm{Ni}_{0.5} \mathrm{Fe}_{0.5} @ \mathrm{COF}$. 


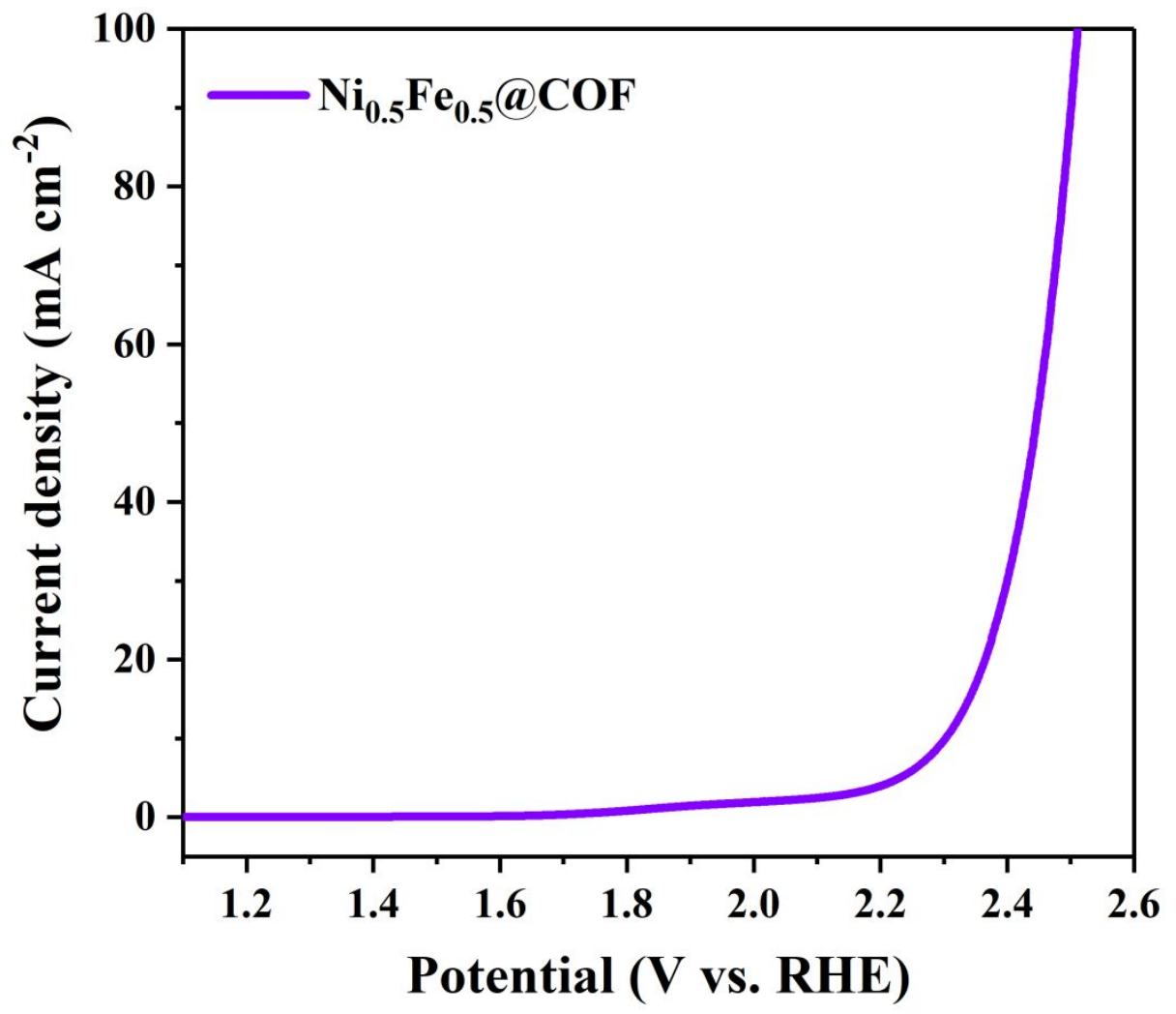

Figure S8. LSV curve of - $\mathrm{SO}_{3} \mathrm{H}$-free $\mathrm{Ni}_{0.5} \mathrm{Fe}_{0.5} @ \mathrm{COF}$. 

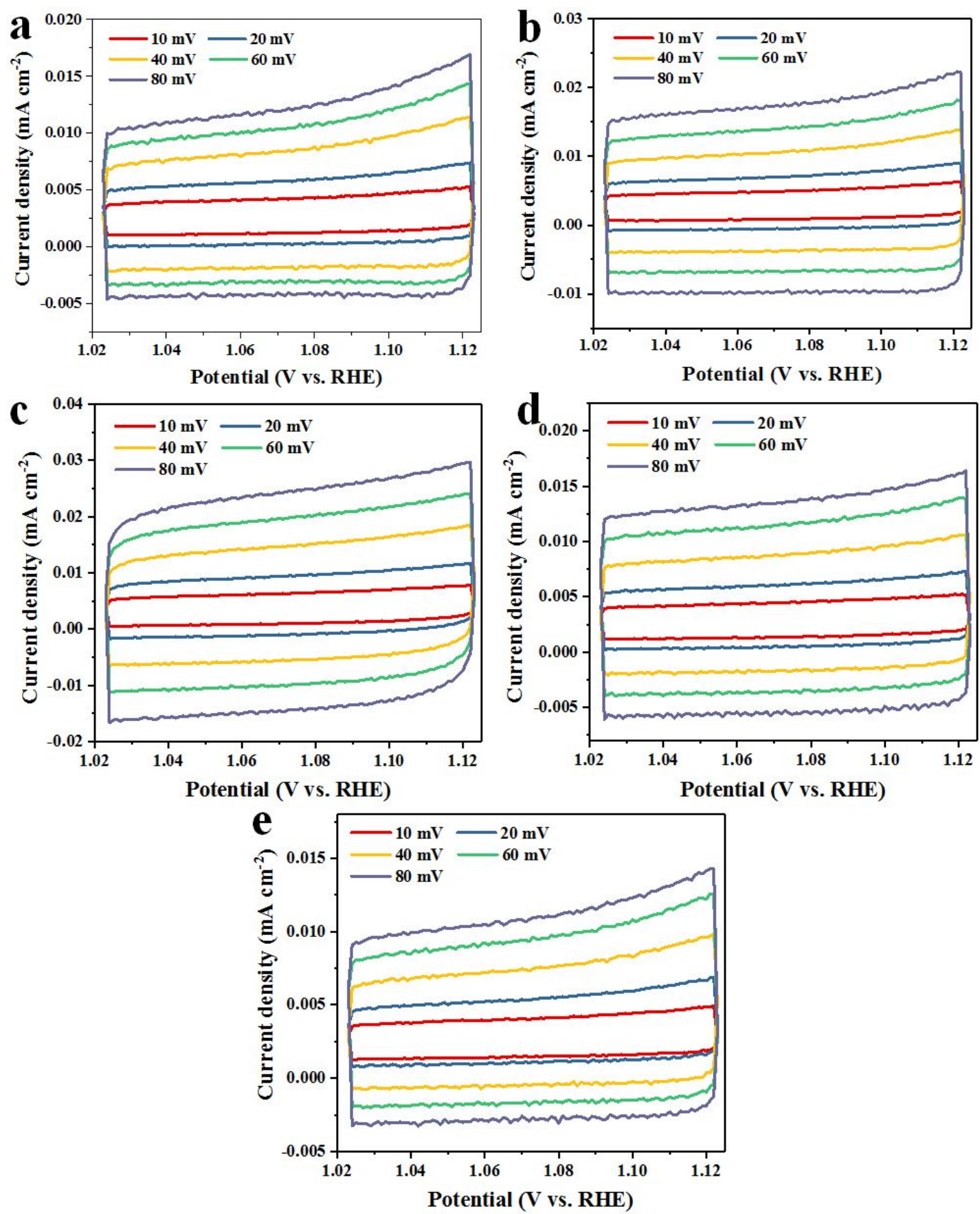

Figure S9. $\mathrm{CV}$ plots of $\mathrm{Ni@COF- \textrm {SO } _ { 3 }}$ (a), $\mathrm{Ni}_{0.8} \mathrm{Fe}_{0.2} @ \mathrm{COF}-\mathrm{SO}_{3} \quad$ (b), $\mathrm{Ni}_{0.5} \mathrm{Fe}_{0.5} @ \mathrm{COF}-\mathrm{SO}_{3}(\mathrm{c}), \mathrm{Ni}_{0.2} \mathrm{Fe}_{0.8} @ \mathrm{COF}-\mathrm{SO}_{3}(\mathrm{~d})$ and $\mathrm{Fe} @ \mathrm{COF}-\mathrm{SO}_{3}$ (e) tested at various scan rates from 10 to $80 \mathrm{mV} \mathrm{s}^{-1}$. 


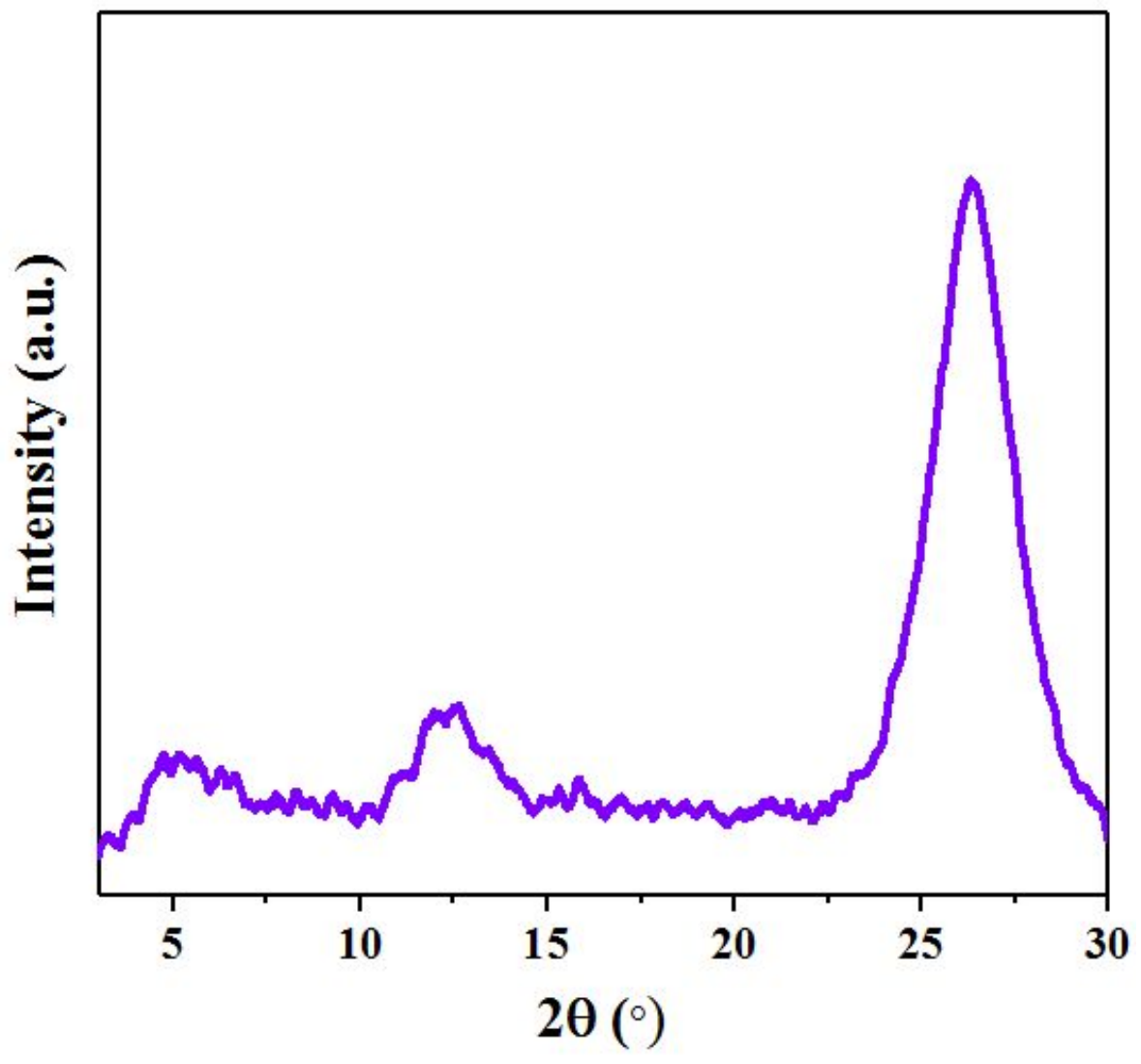

Figure S10. PXRD image of $\mathrm{Ni}_{0.5} \mathrm{Fe}_{0.5} @ \mathrm{COF}-\mathrm{SO}_{3}$ after chronoamperometric measurement. 


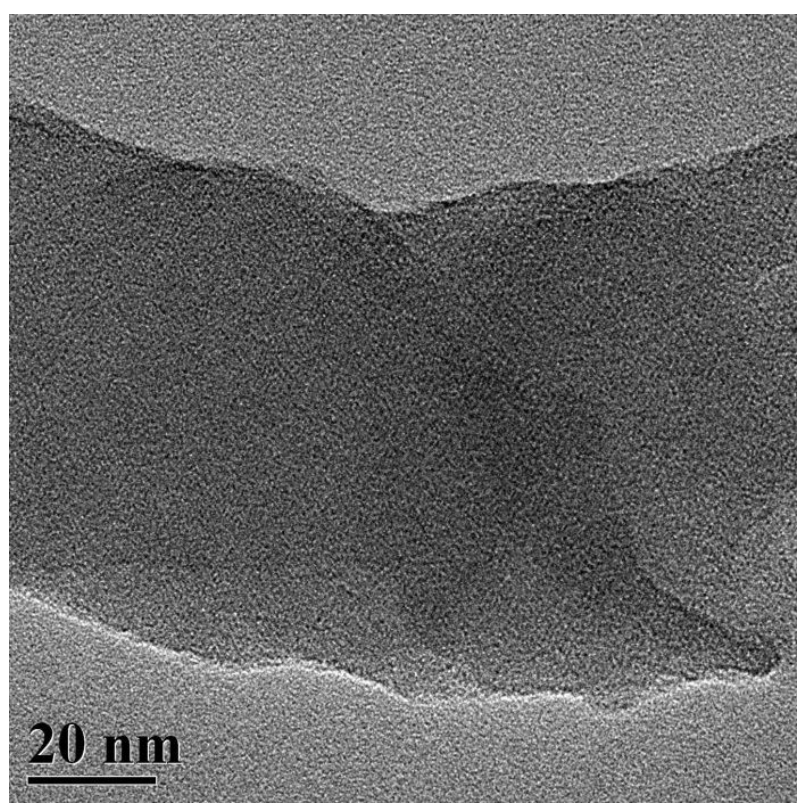

Figure S11. HRTEM image of $\mathrm{Ni}_{0.5} \mathrm{Fe}_{0.5} @ \mathrm{COF}-\mathrm{SO}_{3}$ after chronoamperometric measurement. 


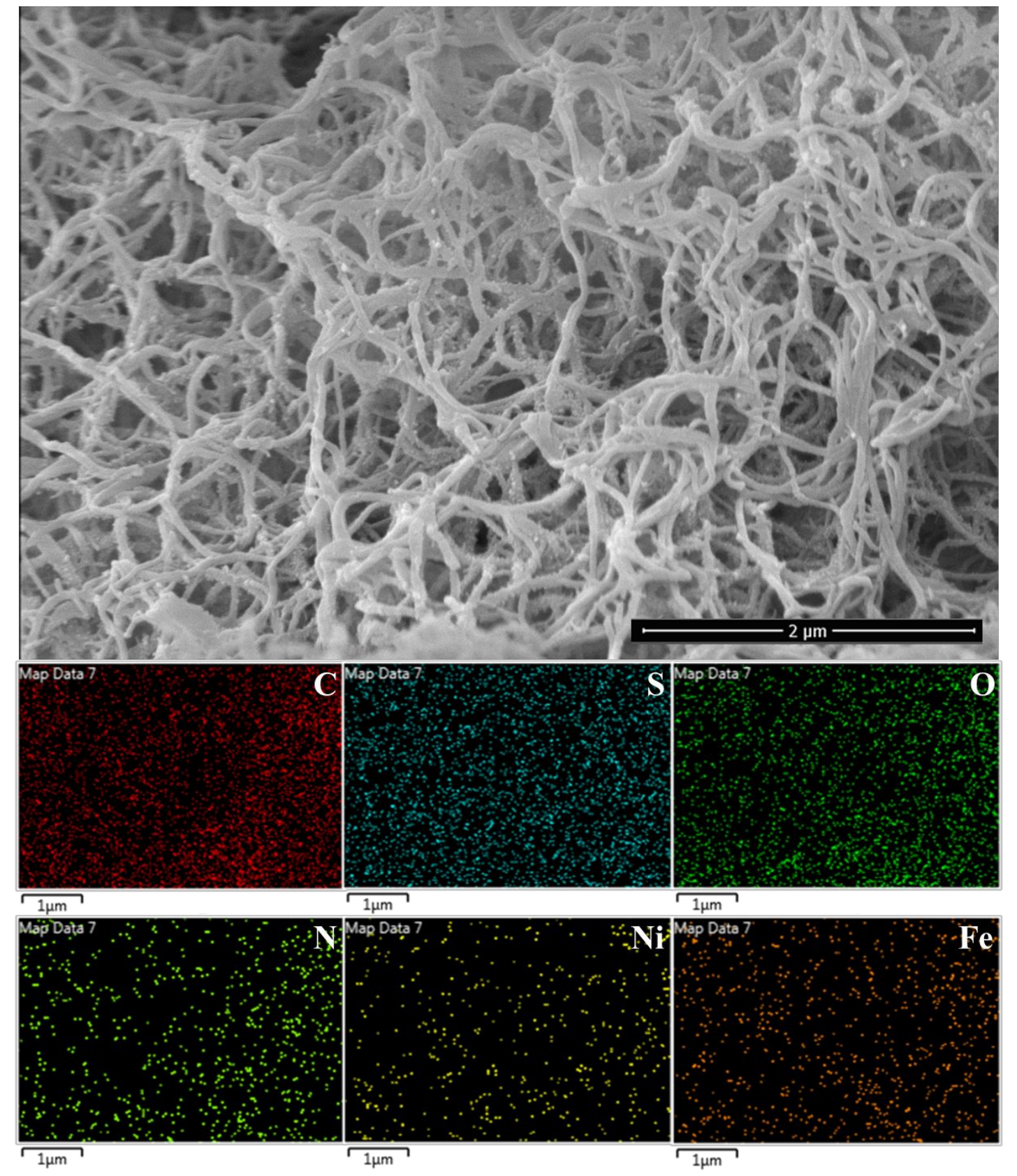

Figure S12. SEM image and SEM-EDS mapping of $\mathrm{Ni}_{0.5} \mathrm{Fe}_{0.5} @ \mathrm{COF}-\mathrm{SO}_{3}$ after OER stability test. 

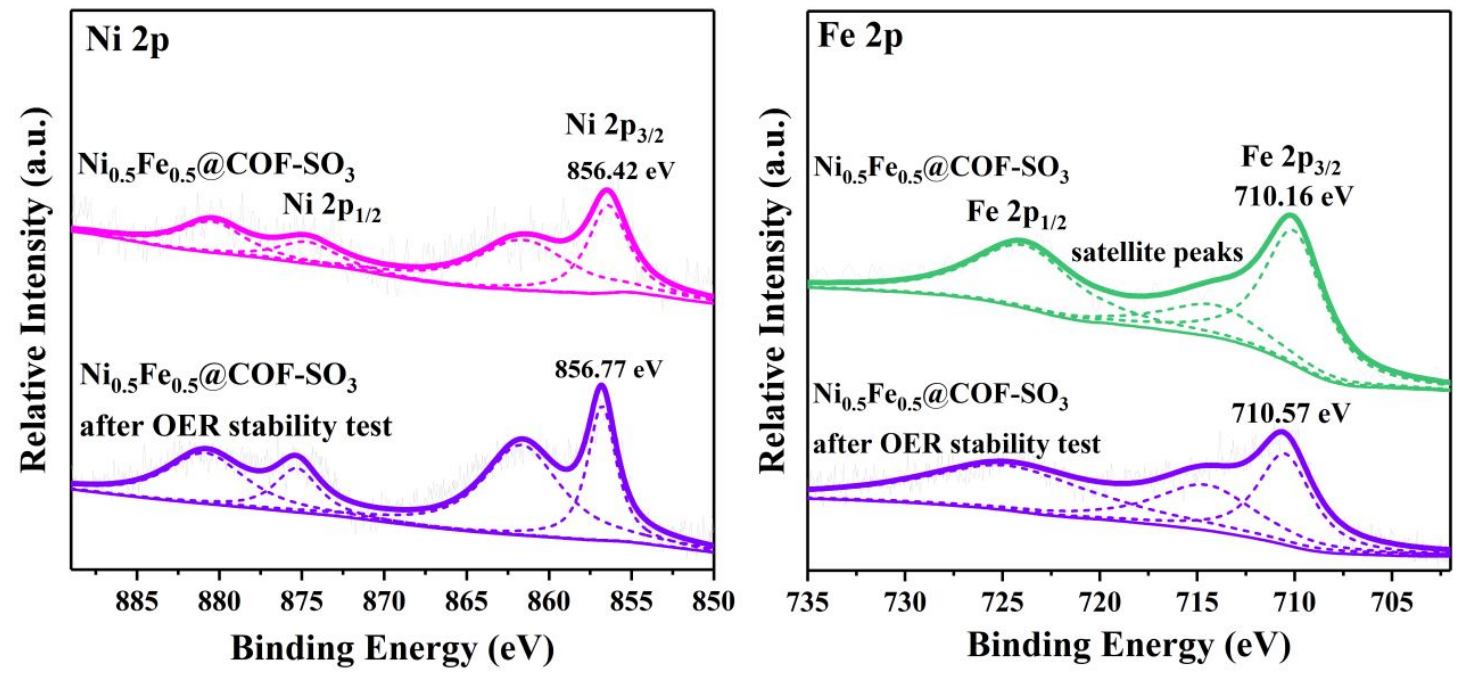

Figure S13. High-resolution Ni 2p and Fe 2p spectra in $\mathrm{Ni}_{0.5} \mathrm{Fe}_{0.5} @ \mathrm{COF}-\mathrm{SO}_{3}$ before and after OER stability test. 


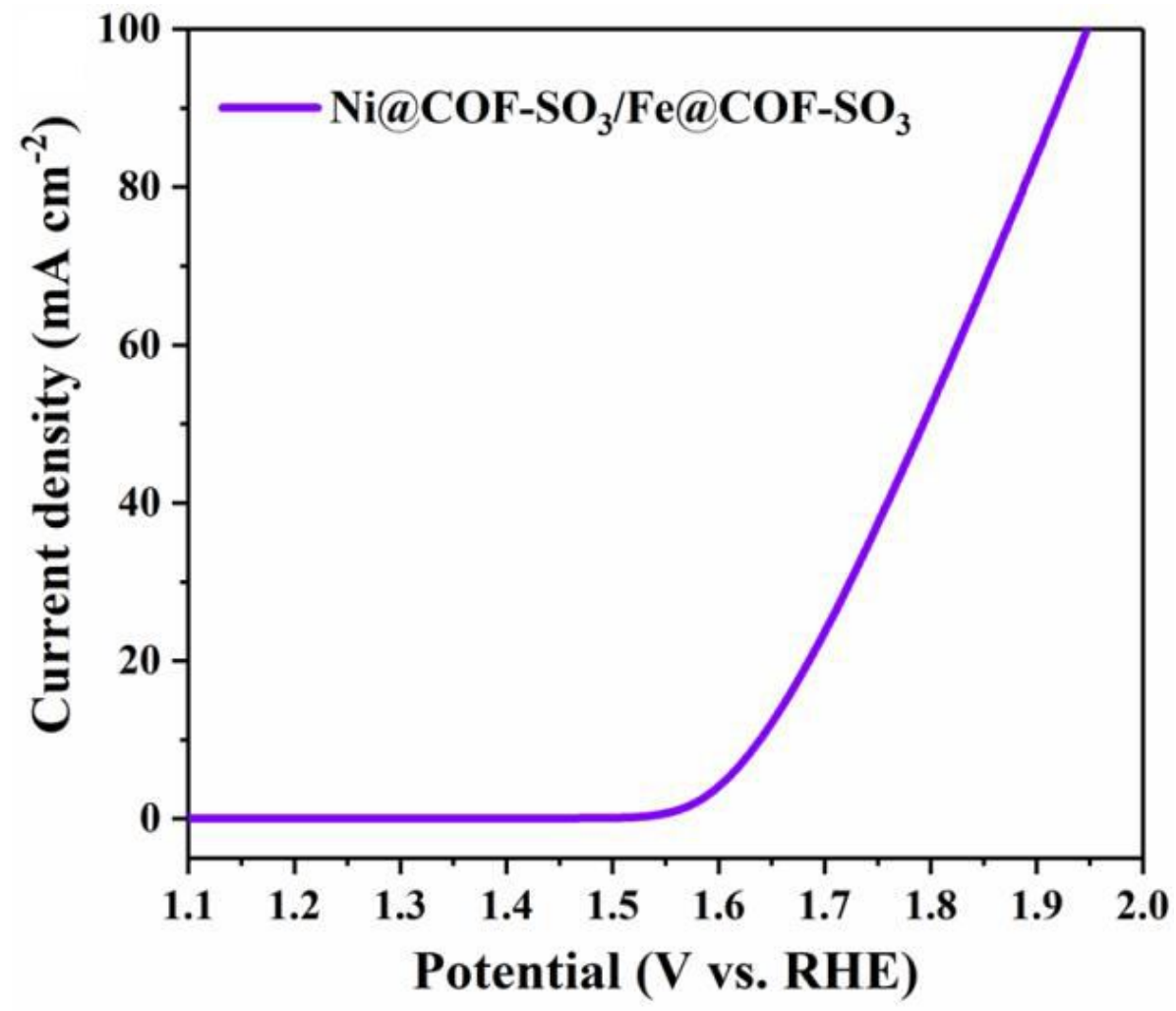

Figure S14. LSV curves of the mechanical mixtures of $\mathrm{Ni} @ \mathrm{COF}-\mathrm{SO}_{3} / \mathrm{Fe} @ \mathrm{COF}-\mathrm{SO}_{3}$ 
Table S1 ICP-AES results of different COFs.

\begin{tabular}{|c|c|c|c|}
\hline \multirow{2}{*}{ Catalyst } & \multicolumn{2}{|c|}{ Content (wt.\%) } & \multirow{2}{*}{$\mathrm{Ni} / \mathrm{Fe}$ mass ratio } \\
\hline & $\mathrm{Ni}$ & $\mathrm{Fe}$ & \\
\hline $\mathrm{Ni@COF-SO}$ & 4.87 & 0 & $4.87 / 0$ \\
\hline $\mathrm{Fe} @ \mathrm{COF}-\mathrm{SO}_{3}$ & 0 & 5.17 & $0 / 5.17$ \\
\hline $\mathrm{Ni}_{0.2} \mathrm{Fe}_{0.8} @ \mathrm{COF}-\mathrm{SO}_{3}$ & 1.04 & 4.20 & $0.2 / 0.81$ \\
\hline $\mathrm{Ni}_{0.5} \mathrm{Fe}_{0.5} @ \mathrm{COF}-\mathrm{SO}_{3}$ & 2.68 & 2.52 & $0.5 / 0.43$ \\
\hline $\mathrm{Ni}_{0.8} \mathrm{Fe}_{0.2} @ \mathrm{COF}-\mathrm{SO}_{3}$ & 4.13 & 1.02 & $0.8 / 0.2$ \\
\hline $\mathrm{Ni}_{0.5} \mathrm{Fe}_{0.5} @ \mathrm{COF}$ & 0 & 0 & 0 \\
\hline
\end{tabular}


Table S2. Comparison of the OER activities of recently reported highly active catalysts in $1.0 \mathrm{KOH}$.

\begin{tabular}{|c|c|c|c|c|c|c|}
\hline Catalysts & $\begin{array}{l}\text { Overpotential } \\
\text { at } 10 \mathrm{~mA} \mathrm{~cm}{ }^{-2} \\
\text { (mV vs. RHE) }\end{array}$ & $\begin{array}{l}\text { Tafel slope } \\
\left(\mathrm{mV} \mathrm{dec}^{-1}\right)\end{array}$ & $\begin{array}{l}\text { Mass } \\
\text { loading (mg } \\
\left.\mathrm{cm}^{-2}\right)\end{array}$ & Substrate & $\begin{array}{l}\text { TOF }\left(10^{-2} \mathrm{~s}^{-1}\right) \text { at } \\
\text { overpotential of } \\
300 \mathrm{mV}\end{array}$ & Reference \\
\hline $\mathrm{Ni}_{0.5} \mathrm{Fe}_{0.5} @ \mathrm{COF}-\mathrm{SO}_{3}$ & 308 & 83 & 0.15 & $\begin{array}{l}\text { carbon } \\
\text { cloth }\end{array}$ & 14 & This work \\
\hline Co-PDY & 270 & 99 & - & $\begin{array}{l}\text { copper } \\
\text { foams }\end{array}$ & - & $\begin{array}{l}\text { J. Mater. Chem. A } \\
\text { 2019, 7, 5575-5582 }\end{array}$ \\
\hline $\begin{array}{l}\text { macro-TpBpy-Co } \\
0.1 \mathrm{M} \mathrm{KOH}\end{array}$ & 380 & 54 & 0.25 & $\mathrm{GC}$ & - & $\begin{array}{l}\text { J. Am. Chem. Soc. } \\
\text { 2019, 141, 6623-6630 }\end{array}$ \\
\hline Fe1Ni2-BDC & 260 & 35 & 0.255 & $\mathrm{GC}$ & 36@330mV & $\begin{array}{l}\text { ACS Energy Lett.2019, } \\
\text { 4, 285-292 }\end{array}$ \\
\hline MIL-53(FeNi)/NF & $\begin{array}{l}233 \\
\text { at } 50 \mathrm{~mA} \mathrm{~cm}^{-2}\end{array}$ & 31.4 & 2.63 & $\mathrm{Ni}$ foam & $40 @ 252 \mathrm{mV}$ & $\begin{array}{l}\text { Adv. Energy Mater. } \\
\text { 2018, } 8,1800584\end{array}$ \\
\hline MAF-X27-OH & 303 & 83 & 0.21 & $\mathrm{Cu}$ Foil & 1.9 & $\begin{array}{l}\text { J. Am. Chem. Soc. } \\
\text { 2016, } 138,8336 \text {. }\end{array}$ \\
\hline $\mathrm{CoO}_{\mathrm{x}}-\mathrm{ZIF}$ & 318 & 70.3 & 0.04 & GC & $8.2 @ 320 \mathrm{mV}$ & $\begin{array}{l}\text { Adv. Funct. Mater. } \\
\text { 2017, 27, } 1702546\end{array}$ \\
\hline $\begin{array}{l}\text { CTGU-10c2 } \\
0.1 \mathrm{KOH}\end{array}$ & 240 & 58 & 0.14 & $\mathrm{GC}$ & 5.378@240mV & $\begin{array}{l}\text { Angew. Chem. Int. Ed. } \\
\text { 2019, 58, 4227-4231. }\end{array}$ \\
\hline $\begin{array}{l}\text { NNU-23 } \\
0.1 \mathrm{KOH}\end{array}$ & 376 & 77.2 & 1 & $\begin{array}{l}\text { Carbon } \\
\text { cloth }\end{array}$ & $3 @ 400$ mV & $\begin{array}{l}\text { Angew. Chem. Int. Ed. } \\
\text { 2018, } 57,9660 \text {. }\end{array}$ \\
\hline $\mathrm{NiFeLDH/GO}$ & 210 & 42 & 0.25 & $\mathrm{GC}$ & 10 & $\begin{array}{l}\text { ACS Nano 2015, 9, } \\
1977 .\end{array}$ \\
\hline LDHNiFe & 300 & 40 & 0.07 & GC & 7 & $\begin{array}{l}\text { Nat. Commun. 2014, } \\
5,4477 \text {. }\end{array}$ \\
\hline CoMn LDH & 324 & 43 & 0.142 & GC & 7.5 & $\begin{array}{l}\text { J. Am. Chem. Soc. } \\
\text { 2014, 136, } 16481 .\end{array}$ \\
\hline
\end{tabular}

[S1] Gao, Z.; Yu, Z. W.; Huang, Y.; He, X.; Su, X.; Xiao, L.; Yu, Y.; Huang, X.; Luo, F. J. Mater. Chem. A DOI: 10.1039/C9TA14023A. 